\title{
A Review of the Side Effects of COVID-19 in Infected Individuals
}

\begin{abstract}
Background: Patients with coronavirus disease are more likely to have multiple problems after recovery. Numerous studies conducted on coronaviruses, especially severe acute respiratory syndrome coronavirus 2 (SARS-CoV-2), which has spread rapidly around the world, have motivated us to gather and provide information in the form of a review article.

Method: In this study a rapid review study on the complications of coronavirus disease was performed in published research articles in Latin and Persian in the period 2001-2020 were conducted in databases. Out of 61 research articles found, 31 articles were reviewed evaluate.

Results: In a number of patients, sometimes severe side effects emerge after the disease onset, and their quality of life may be affected for years. COVID-19 causes a variety of disorders, including respiratory, intestinal, renal, cardiovascular, and neurological diseases. Severe cardiovascular damages, such as myocardial infarction, arthritis, and heart failure, are also considered the complications of COVID-19. Also, studies have shown that the social, individual, economic, and health effects of the disease remain in the community for many years. The disease causes cardiovascular, hepatic, and neurological complications in individuals infected by the virus.

Conclusion: In this review, we focused on short- and long-term complications of COVID-19 in patients recovered from the acute phase of COVID-19. Due to these cases, it is very important to study and recognize the side effects of this disease.
\end{abstract}

Keywords:COVID-19, Epidemic ${ }^{\{1\}}$,

Myocardial damage, Arrhythmia ${ }^{\{2\}}$, Liver enzymes
Article Info

Authors:

Mirzaei $S^{1}$ (i)

Bokaie $\mathrm{S}^{2}$ (1)

Hushmandi $\mathrm{K}^{2}$ (1)

Daneshi $\mathrm{S}^{3}$ 이

Raei $\mathrm{M}^{4}$ (1)

Entezari $\mathrm{M}^{5^{*}}$

Received:2020.4.13

Accepted:2020.4.29

E-Published:2020.5.30

\footnotetext{
Affiliations

*Corresponding author: Dr. Maliheh Entezari, Department of Genetics, Faculty of Advanced Science and Technology, Tehran Medical Sciences, Islamic Azad University, Tehran, Iran. mentezari@iautmu.ac.ir
}

\section{Citation Subjects:}

$\{1\}$ Disease Outbreaks

\{2\} Cardiac Arrhythmia 
فصلنامه يرستار و گيزشك در رزم / بهار 99 / سال هشتم مقاله مرورى

\section{مرورى بر عوارض جانبى مبتلايان به ويروس كوويد-19}

\section{اطلاعات مقاله - اله}

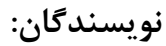

سبيده ميرزائى' نويند

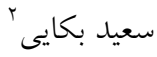

كياوش هوشمندى بكابى

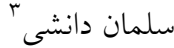

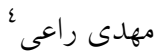

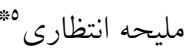

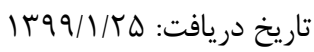

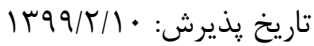

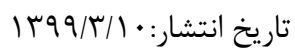

مقدمه: بيماران مبتلا به بيمارى ويروس كرونا بعد از بهبودى دهار مشكلات متعـددى

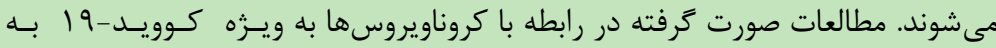

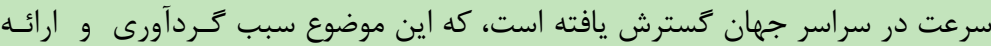
اطلاعات به دست آمده در يك مقاله مرورى كرديد كريد

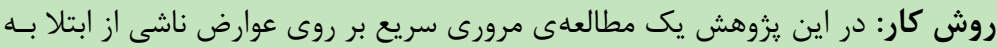

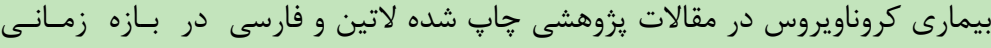

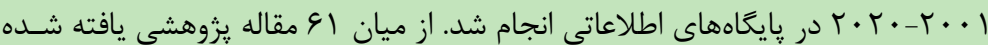

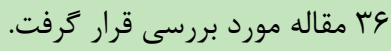

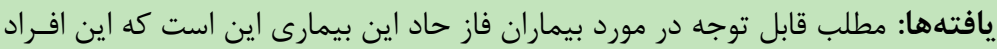

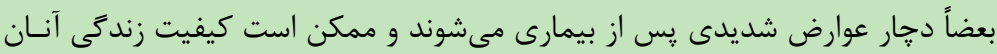

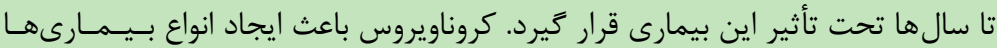

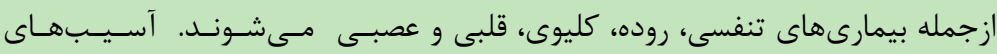

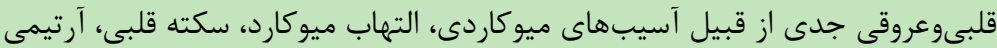

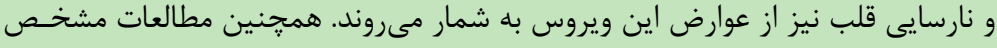

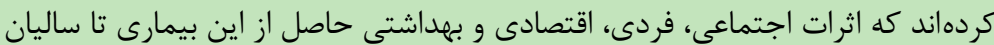
دراز در جوامع باقى مى ماند.

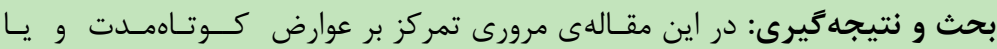

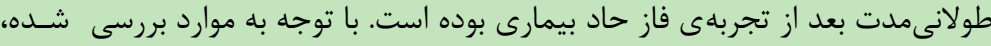

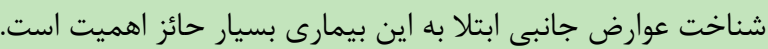

$$
\text { وازَّان كليدى: كوويد-9 1، إيدمى \}1 ، آسيب ميوكارد، آريتمى، آنزيمهاى كبدى }
$$

ا - كروه زيستشناسى، واحد علوم و تحقيقات، دانشكاه آزاد اسلامى، تهران، ايران

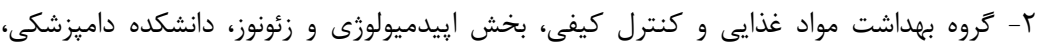
دانشكاه تهران، تهران، ايران

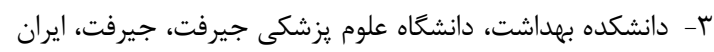

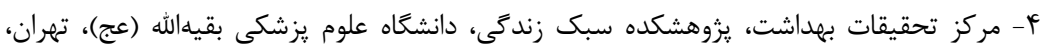
شيوع، هملكَيرى

ه- كروه زنتيك، دانشكده علوم و فنون نوين، دانشكاه آزاد اسلامى، علوم يزشكى تهران، تهران، ايران mentezari@iautmu.ac.ir 
شد. نمونه هاى محيطى از غذاهاى موجود در بازار هووانا از نظــر

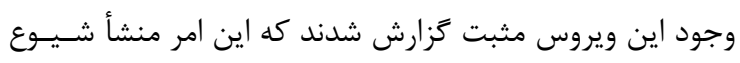
ويروس را مشخص نمود. افزايش تصاعدى بيماران انتقال انسـان

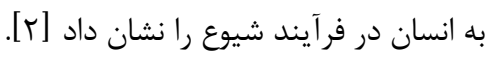

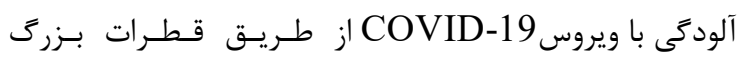

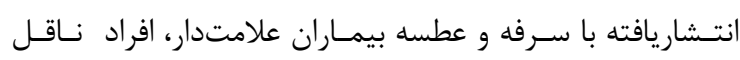

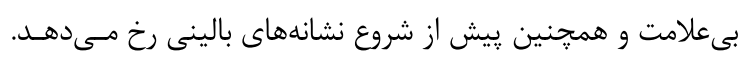

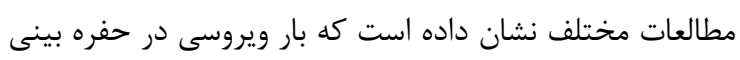

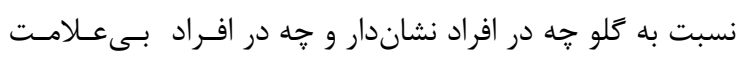

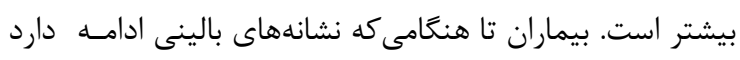

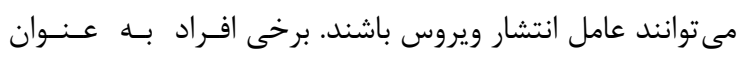

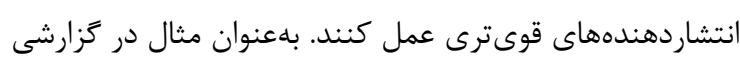

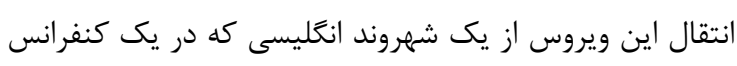

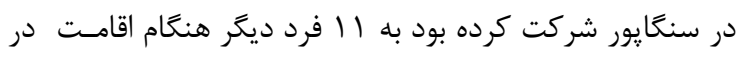

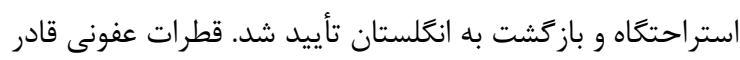

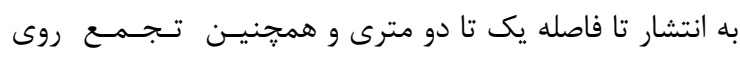

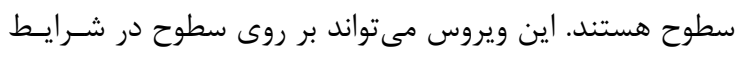

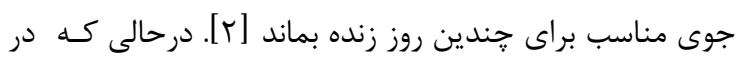

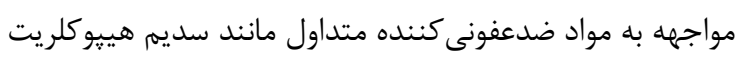

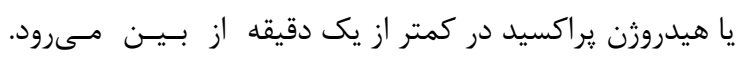

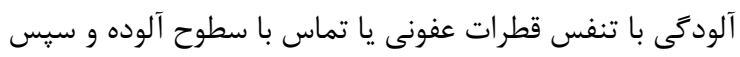

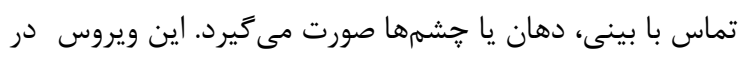

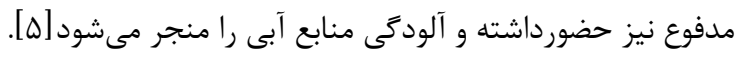

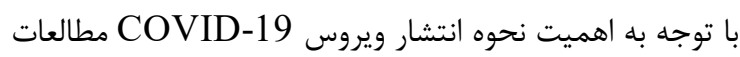

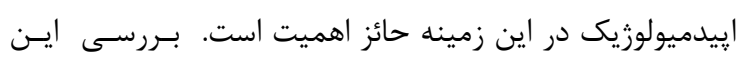

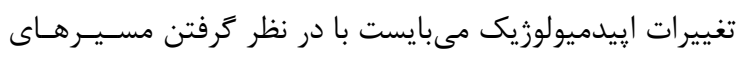

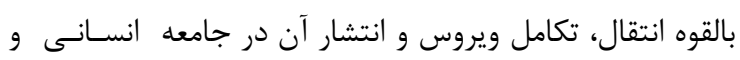

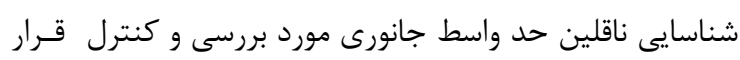

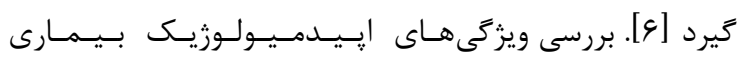

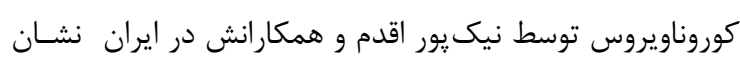

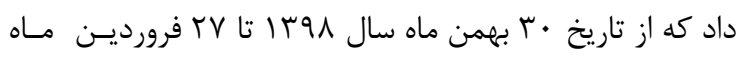

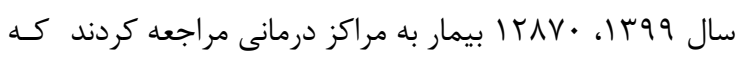

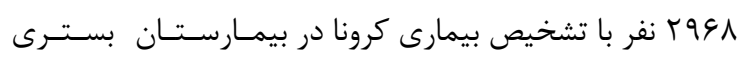

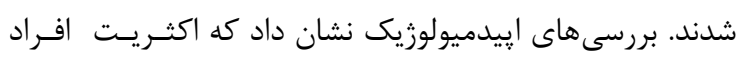

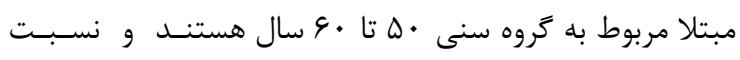

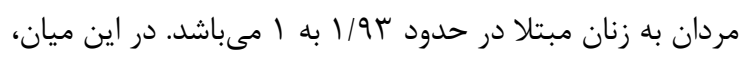

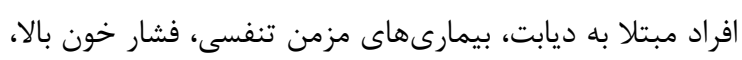

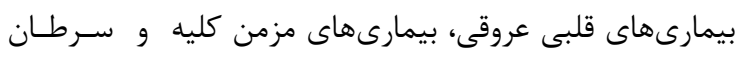

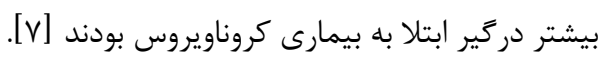

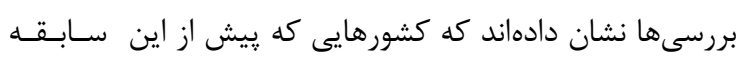

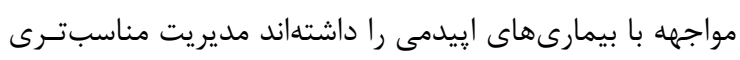
نسبت به اين بيمارى داشته و كسترش بيمارى در اين كشورهـا
مقدمه

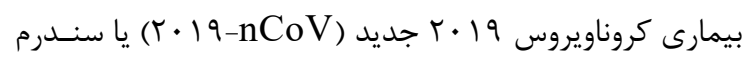

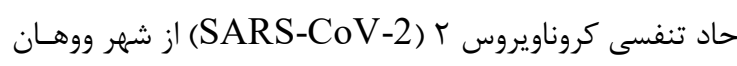

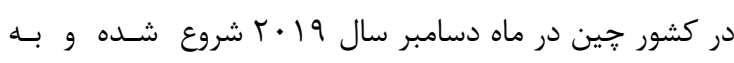

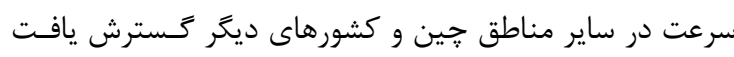

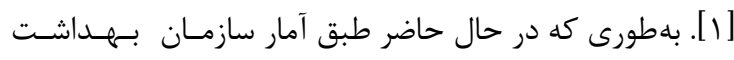

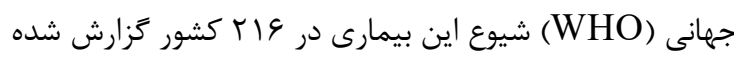

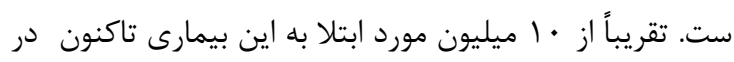

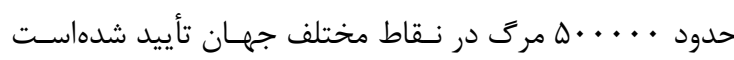

[r]

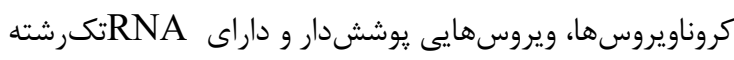

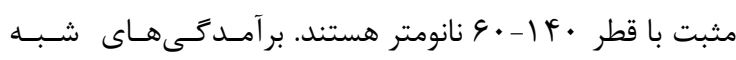

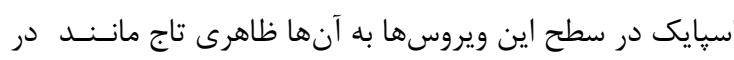

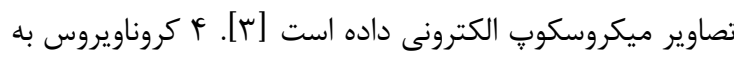

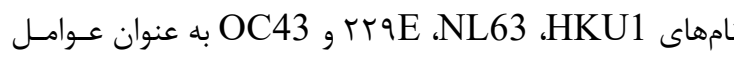

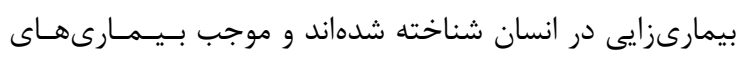

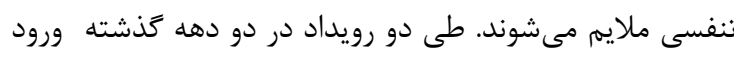

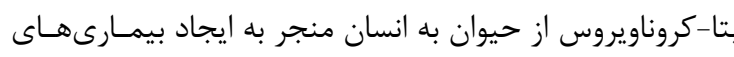

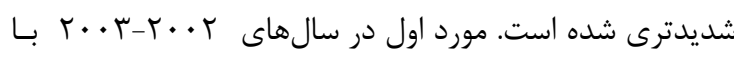

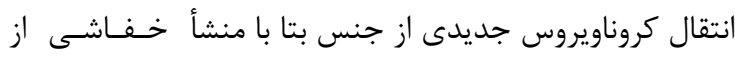

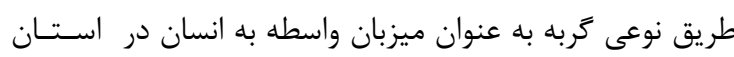

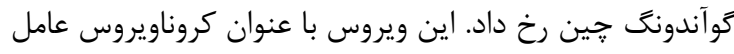

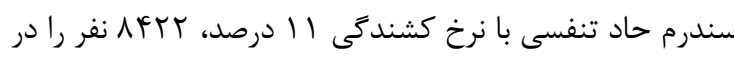

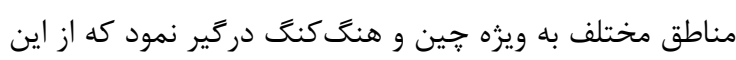

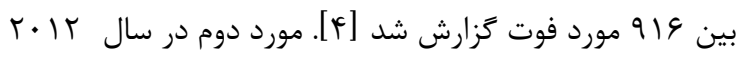
MERS با عنوان كروناويروس عامل سندرم تنفسى خاورميانه (-CoV

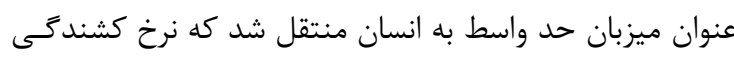

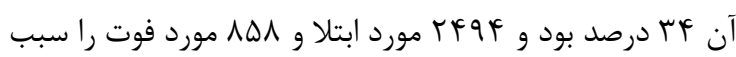

شد [r]

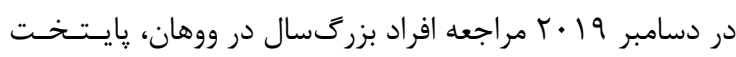
استان هوبى، به عنوان قطب اصلى حملونقل دراجل در خين، با علائسم

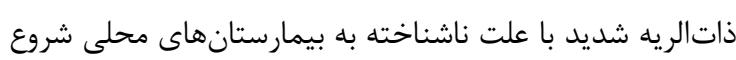

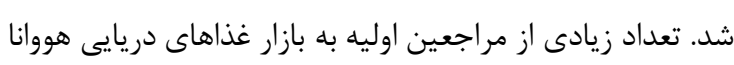

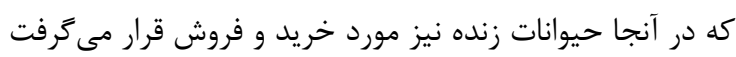

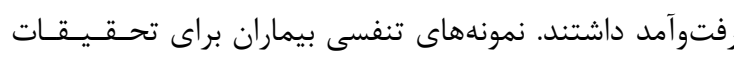

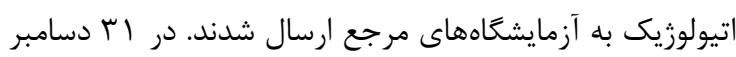

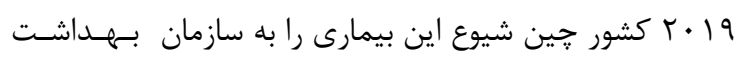

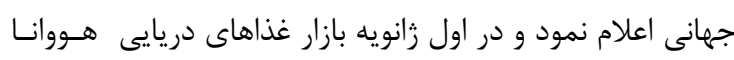

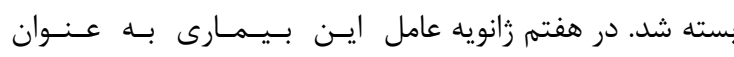

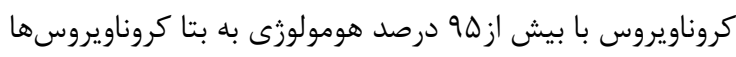

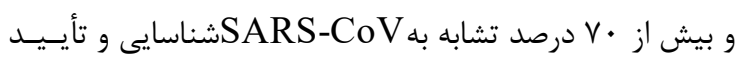


بيماران كزارش شده است. عوارض مشاهده شده از اين بيمـارى

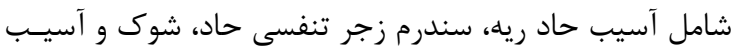

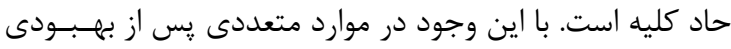

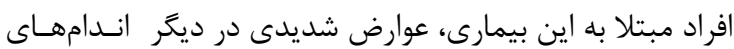

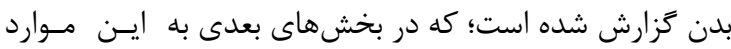

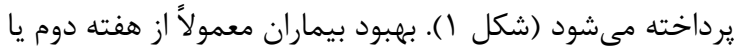

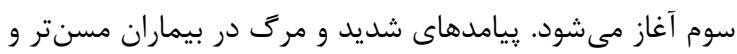

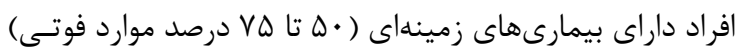

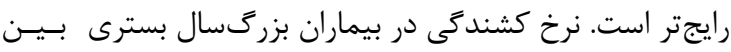

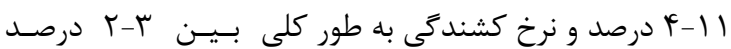

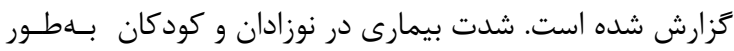

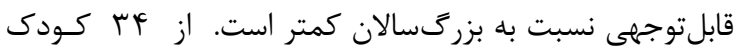

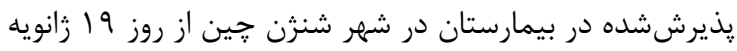

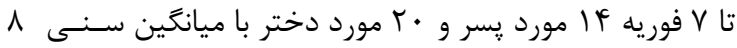

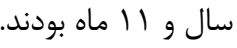

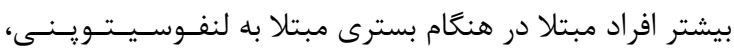

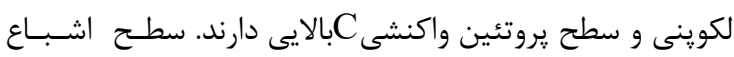

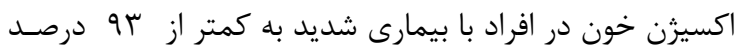

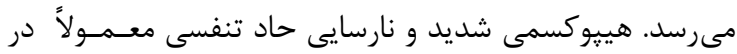

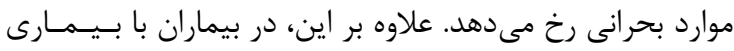

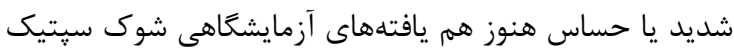

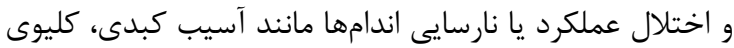

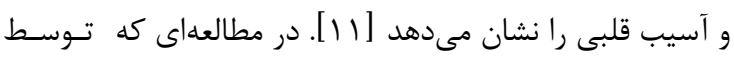

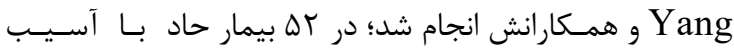

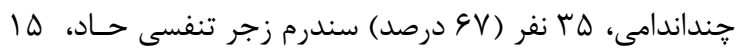

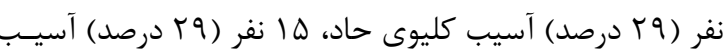

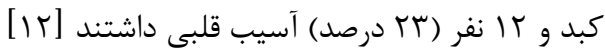

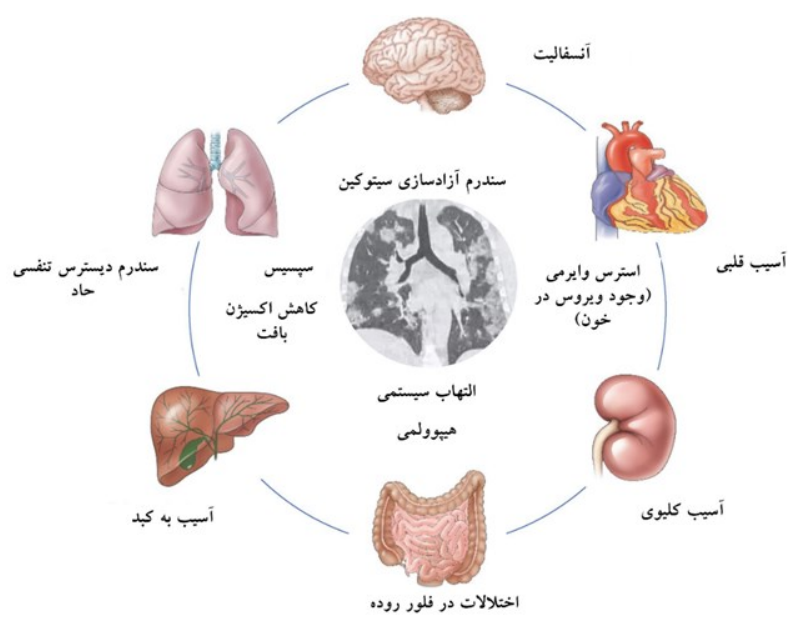

شكل ا. عوارض بيماران مبتلا به

\section{[Li and Fan 2020] COVID-19}

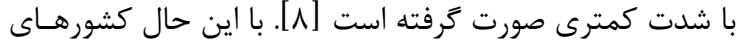

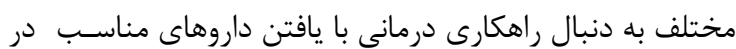

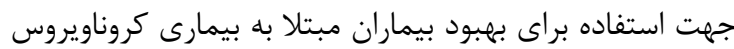

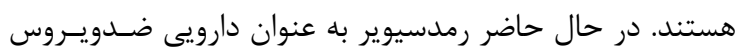

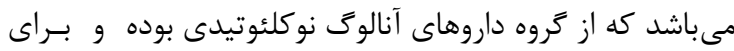

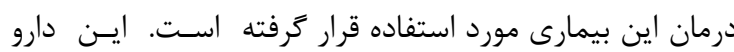

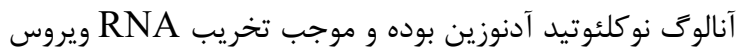

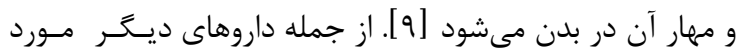

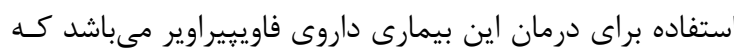

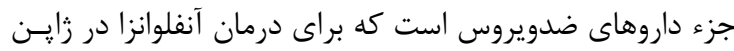

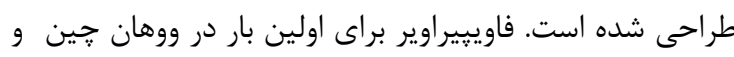

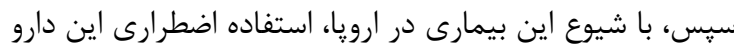

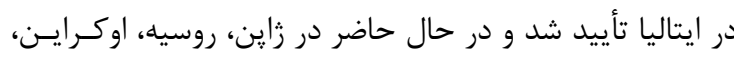

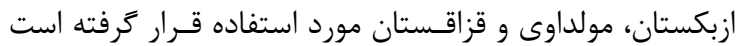

$$
\text { روش كار }
$$

اين جستار يك مقاله مرورى سريع است. اين مقاله با كليدوازهـ-

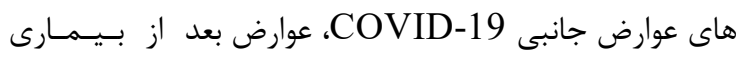

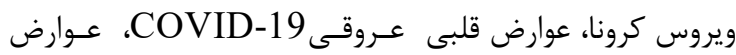

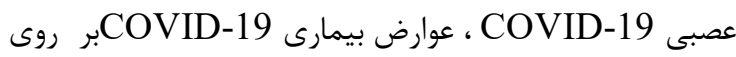
كبد و همجنين علائم بالينى در پايخاههاى اطلاعاتى، Science Web of ،PubMed ،Google Scholar .Direct Science

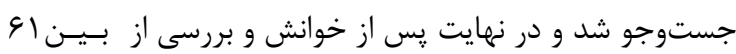

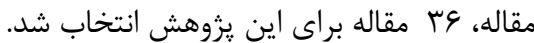

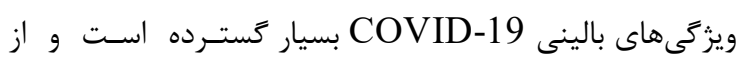

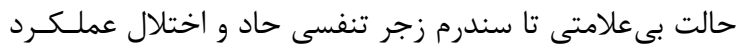

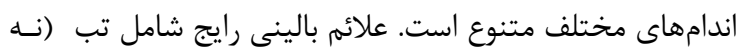

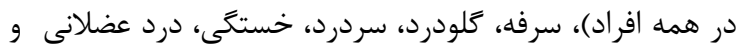

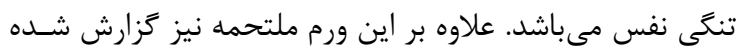

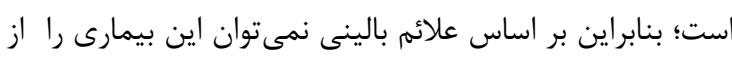

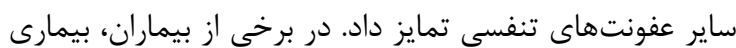

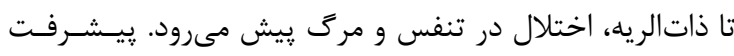

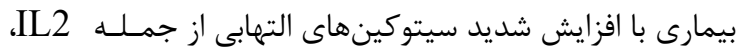
TNF $\alpha$, MIP1A ،MCP1 IT10 GCSF ،IL10 ،IL7 همراه است. ميانكَين زمان از شروع علائم تا تنكى نفس ه هروز تالت

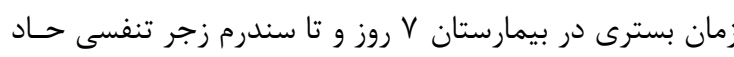

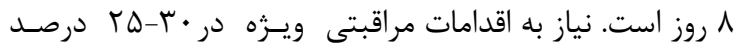




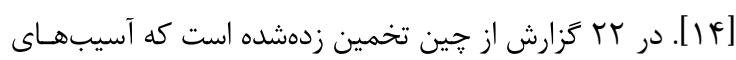

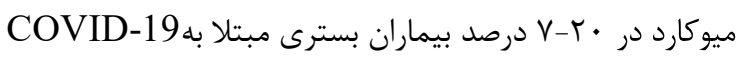

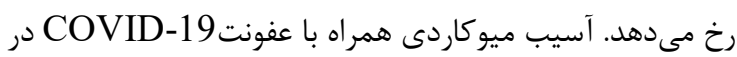

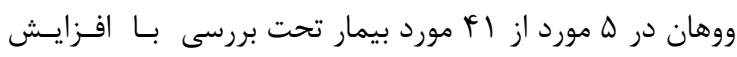
سطح ترويونين ا قلبى با حساسيت بالا (بيش از

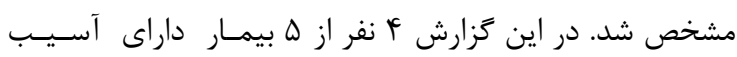

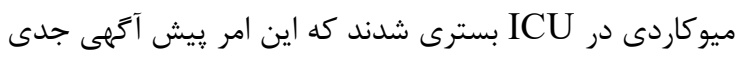

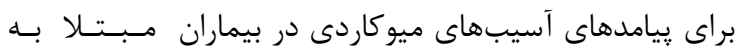

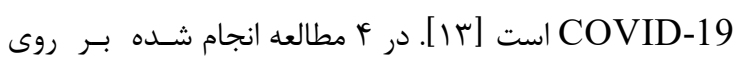
مجموع ال TH بيمار ميانگين سطوح ترويونين ا قلبى در بيماران حاد مبتلا به COVID-19 بهطور جشمخيرى بالاتر بود [ه 1 ].

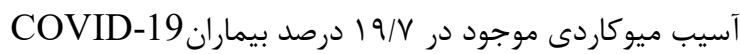

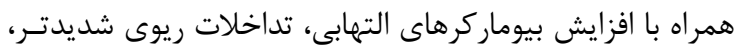

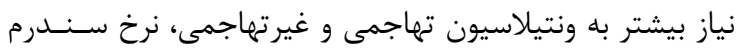

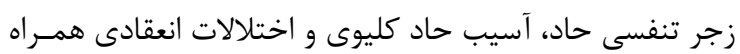

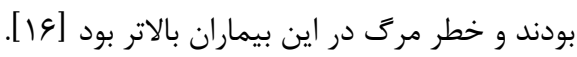

مشكلات قلبى در افراد مبتلا به كوويد-19

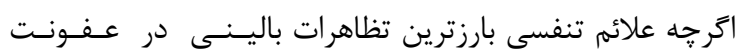
كروناويروسى شناختهشده است با اين حال آسيبهاى قلبسى و و و

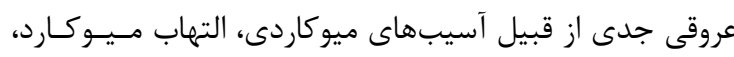

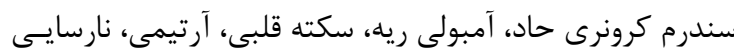

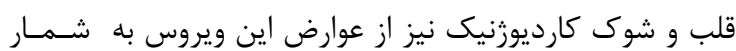

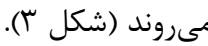

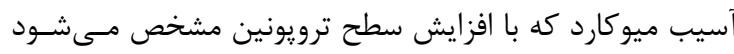

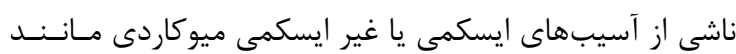

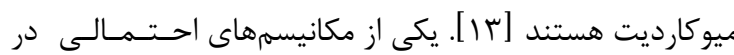
ايجاد آسيبهاى ميوكاردى حاد در عفونتهاى

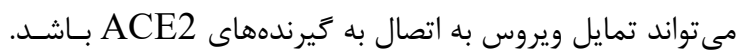

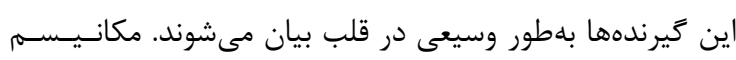

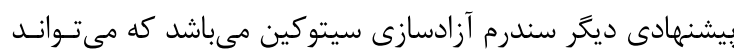

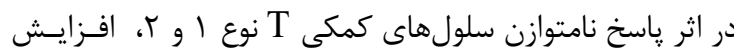

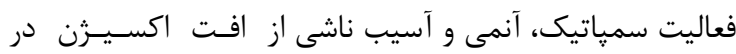

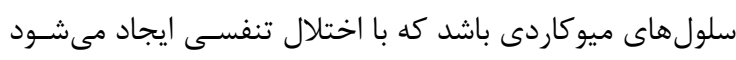

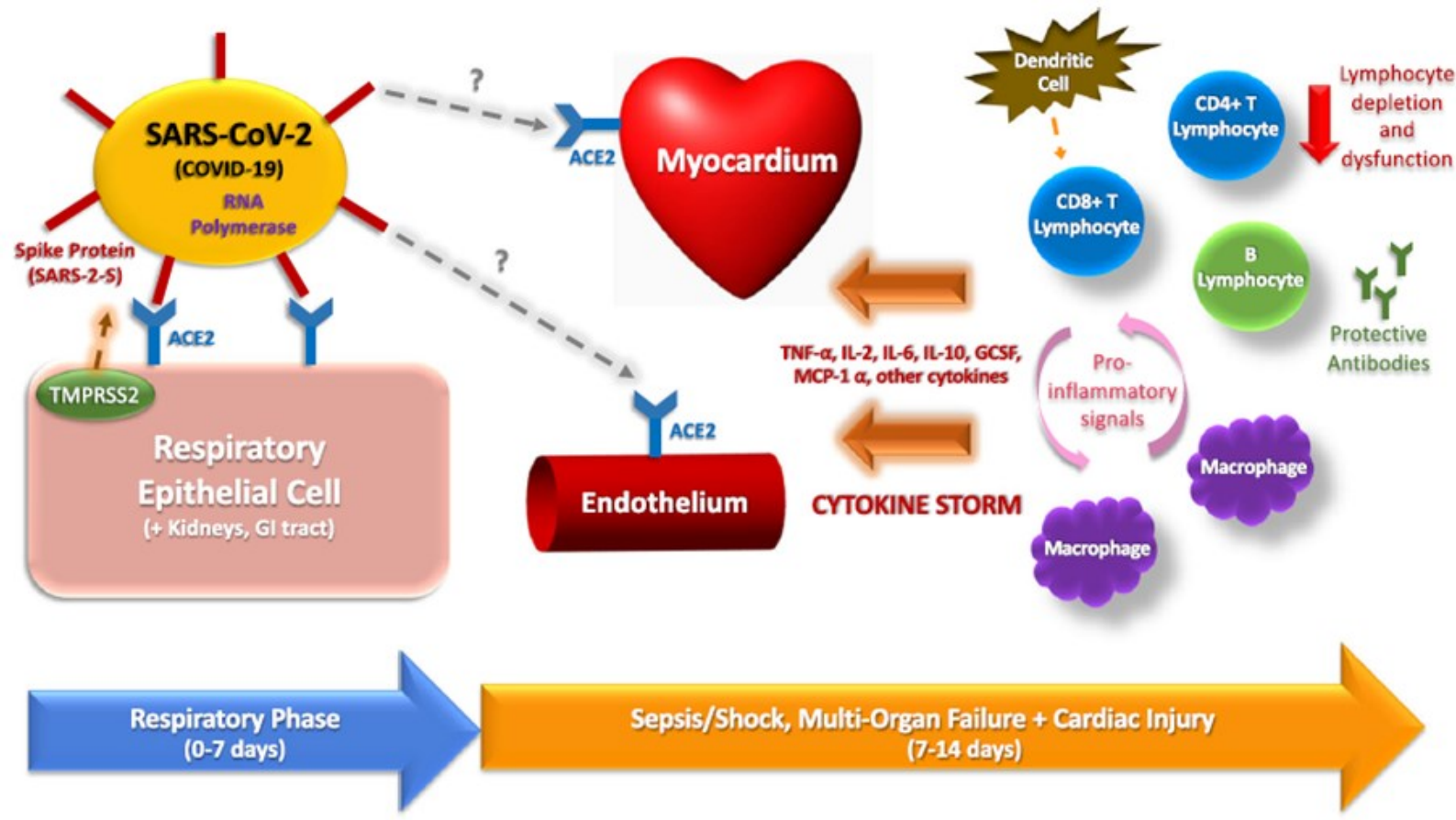

شكل Y.اتصال ويروس COVID-19 به كيرندهای CACE2 در ديواره ركهاى خونى، سلولهاى قلب، كليه و سلولهاى

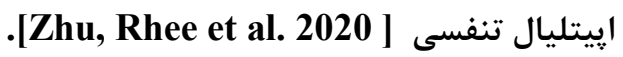

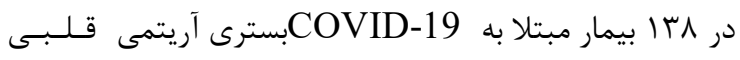

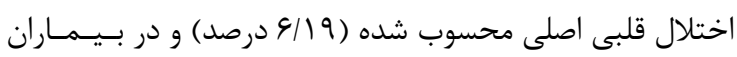

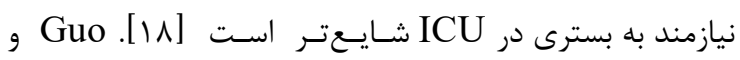

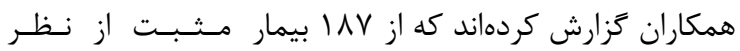

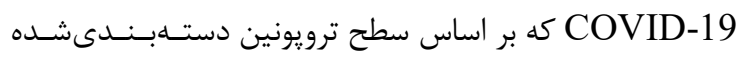

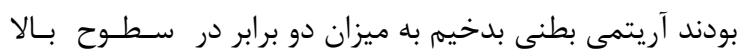

على غم شماى بالينى ميوكارديت در بسيارى از موارد، عفـونـت

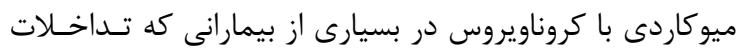

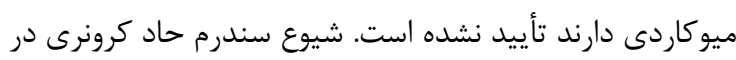

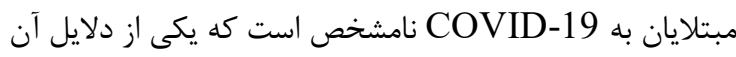

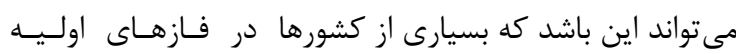

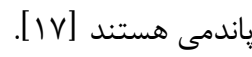




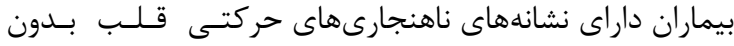

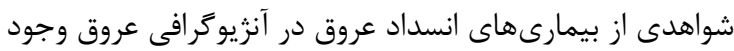

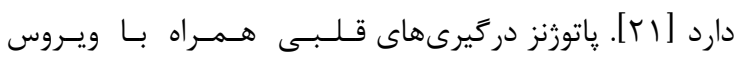

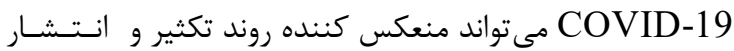

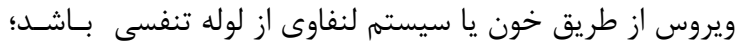

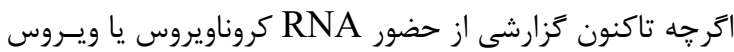

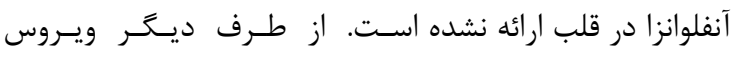

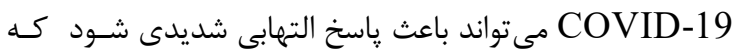

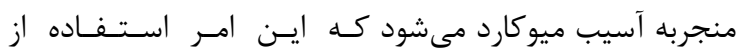

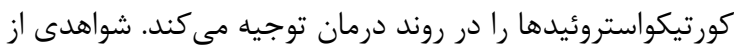

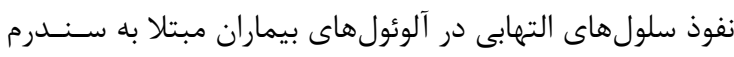

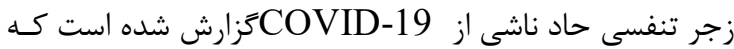

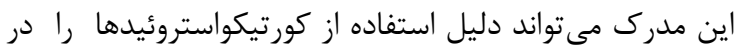

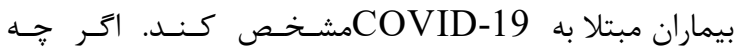
سازوكارهاى فراساختارى قطعى در دسترس نيستند، با اين حال حال

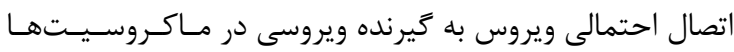

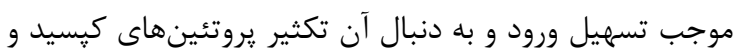

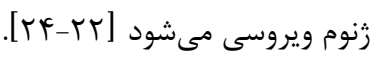

ترويونين شايعتر است (ه/ ال درصد در مقابل ه/ ه درصـد) و و

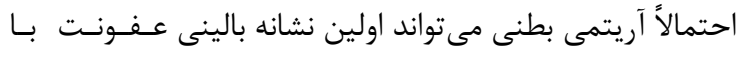

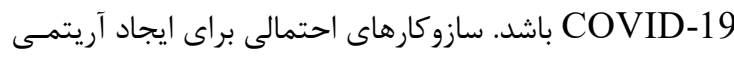

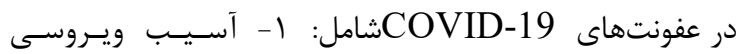

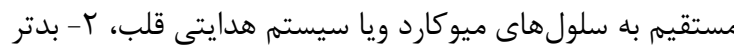

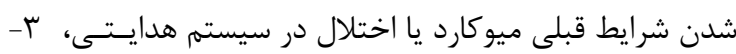

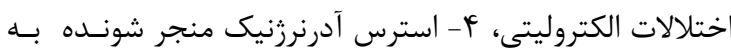

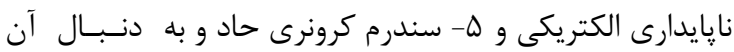
ايسكمى باشد [19].

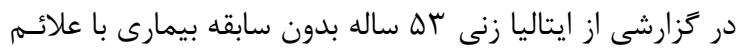

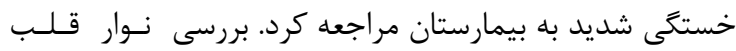

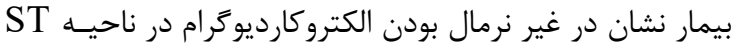

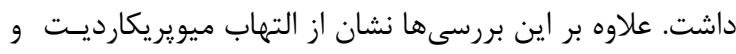

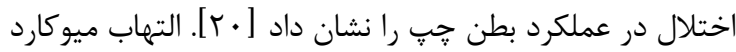

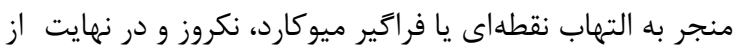

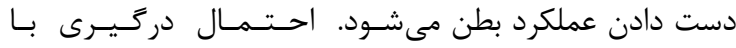

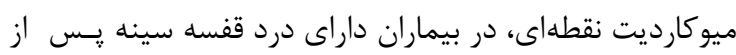

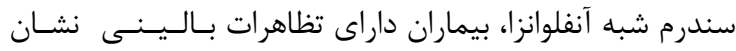

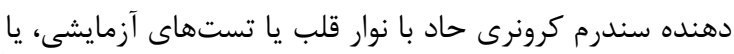
ميو كارديت
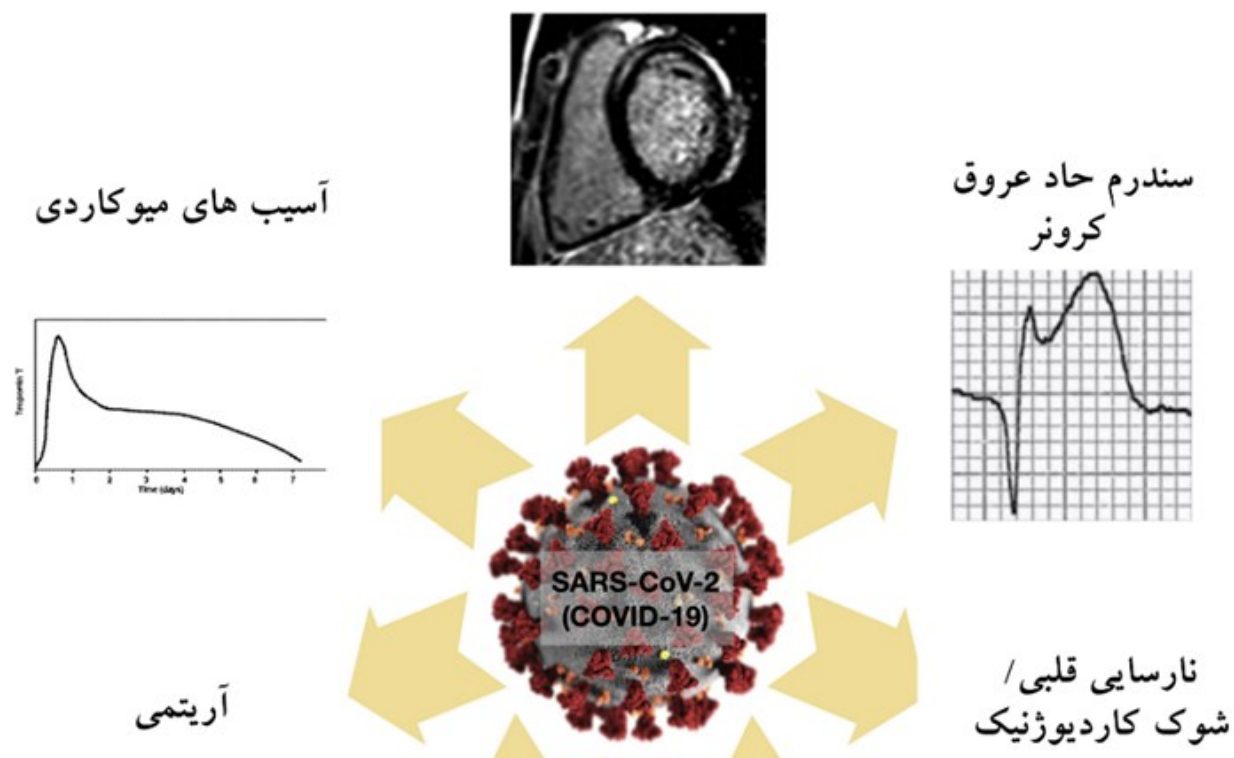

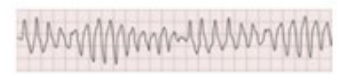
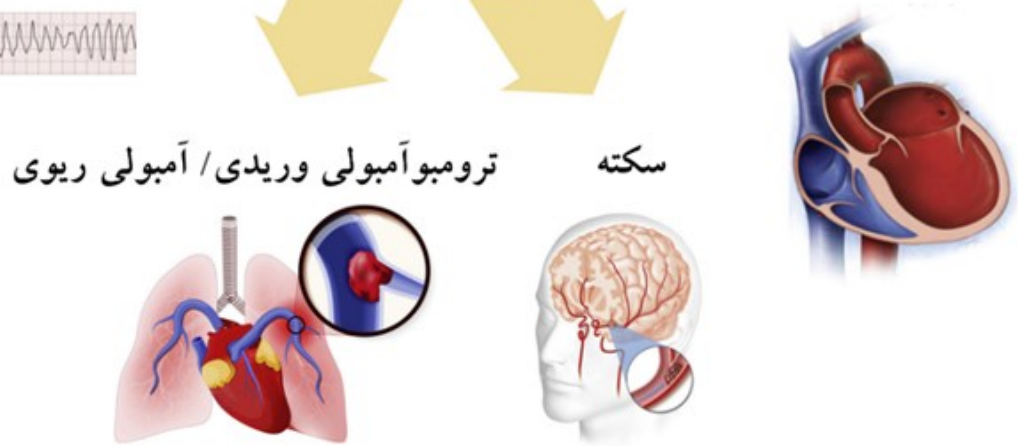

شكل r. تظاهرات قلبى عروقى مر تبط با عفونتBoukhris, Hillani et al. 2020] COVID-19] ]. 


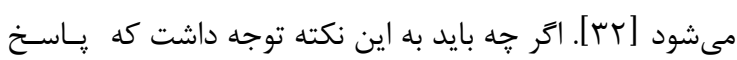

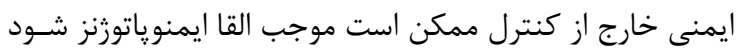

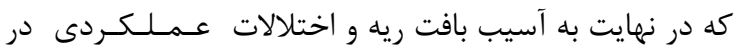

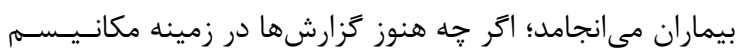
ايمنىزايى در آسيبهاى كبدى در عفونستهـاى اندى است [11]. تغييرات بيوشيميايى در مبتلايان به SARS و MERS نـيـز

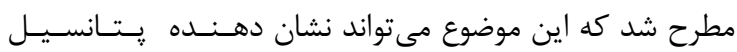

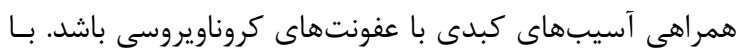

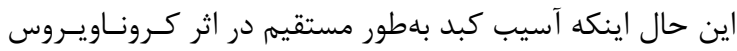

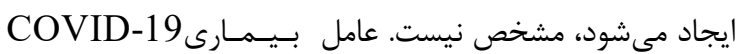

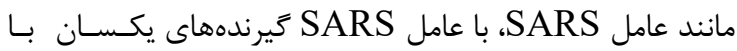

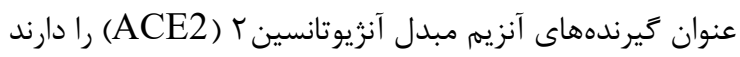

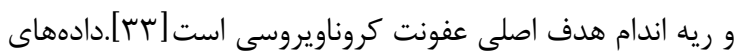

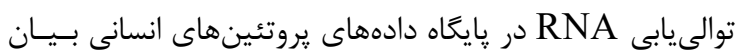
ACE2 در سلولهاى كبد را نشان داده است [11].

عوارض بيمارى ويروس كوويد-19 بر سيستم عصبى

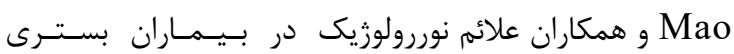

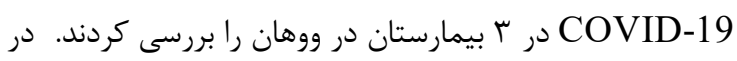

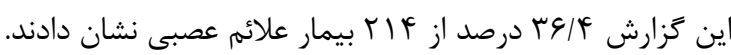

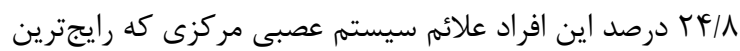

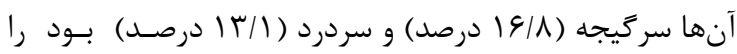

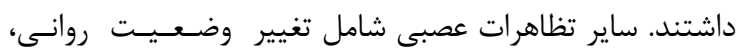

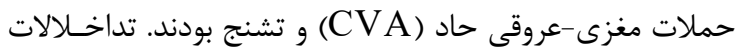
سيستم عصبى مركزى به جز AMS و بيمارى به ويزه در بيماران شديد خود را نشان داد. در حالى كه به

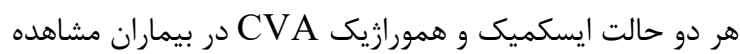
شد، حملات ايسكميك رايجتر بوده است. بهطور ويثه در بيماران شديدتر با علائم سيستم عصبى مركزى كاهش تعداد لنفوسيتهـا،

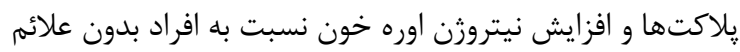
COVID- عصبى گزارش شده است. در اين مطالعه اثر عفونت

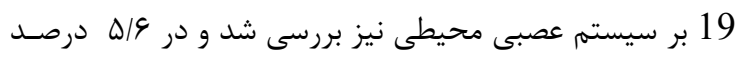

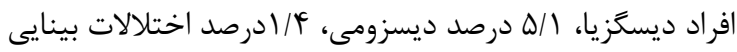

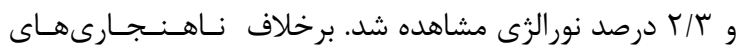

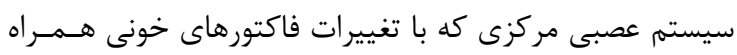

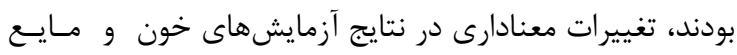

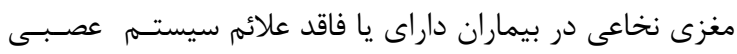

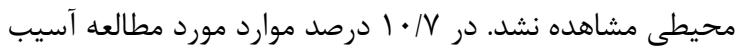

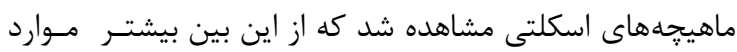

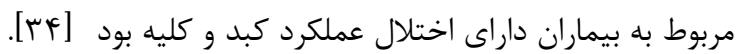

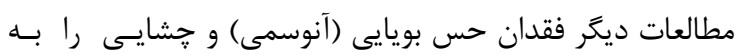

\section{عوارض كبدى ناشى از كوويد-19}

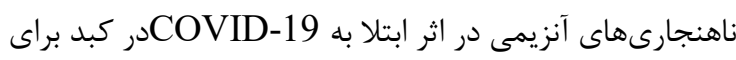

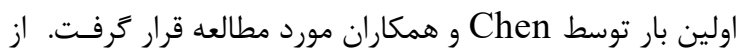

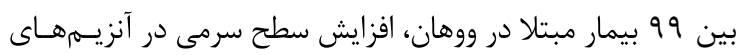

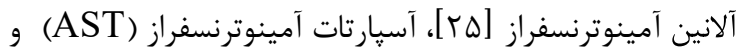

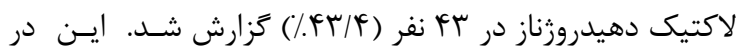

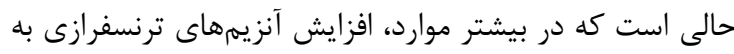

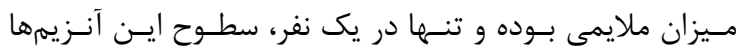

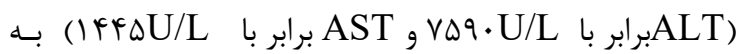

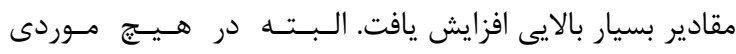

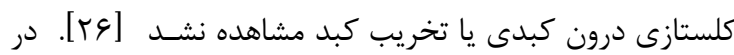

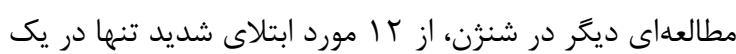

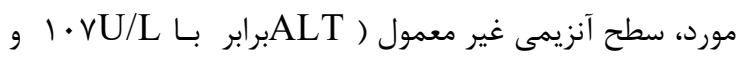

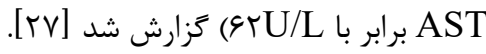

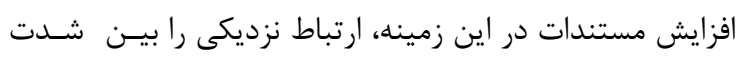

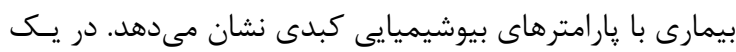

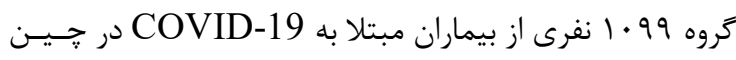

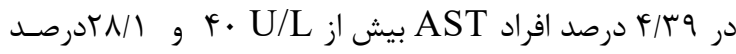

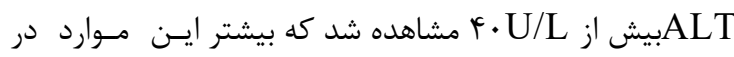

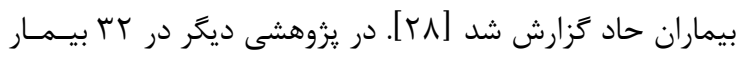

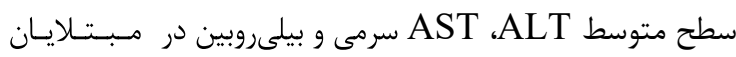

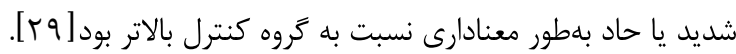

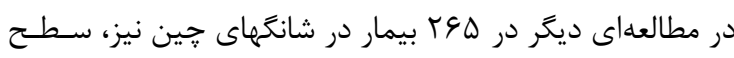

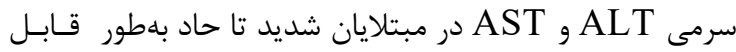

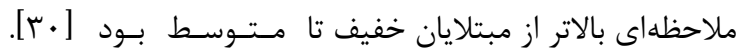

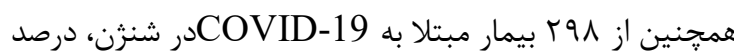

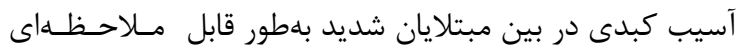

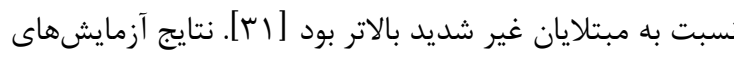

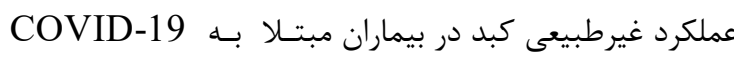

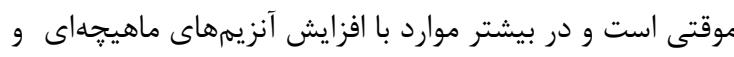

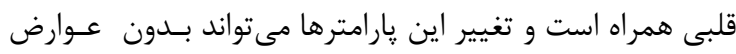

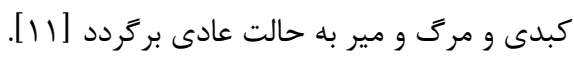

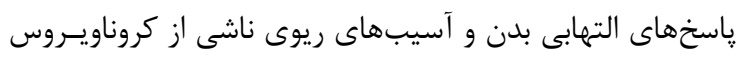

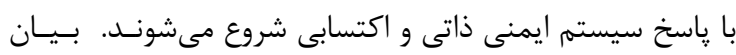

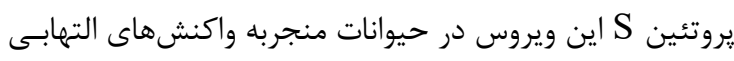

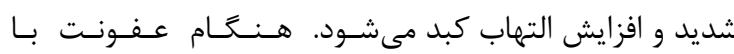

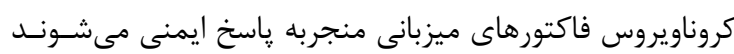

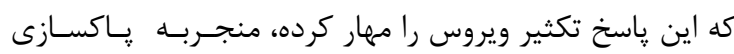

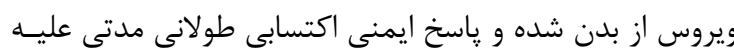

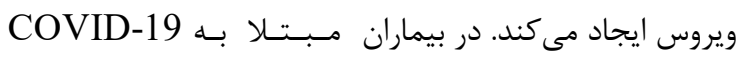

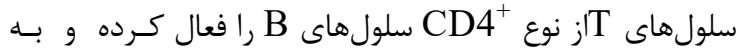
دنبـال آن توليد آنتىبادىهاى اختصاصى عليه ويسروس آغـاز 
Guan آسيبهاى ماهيجهاه اسكلتى با عفونست

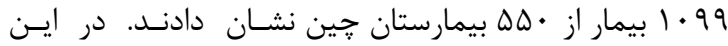

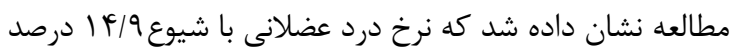

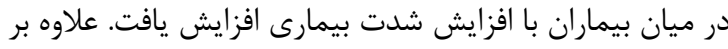

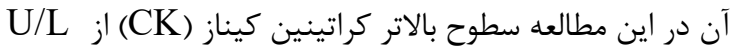

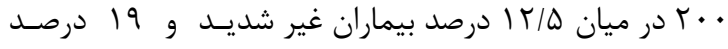

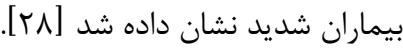

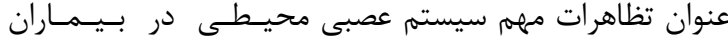
COFID-19

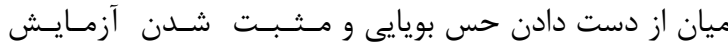

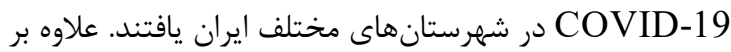

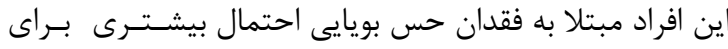

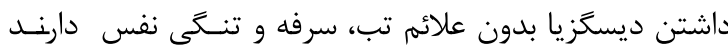

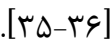

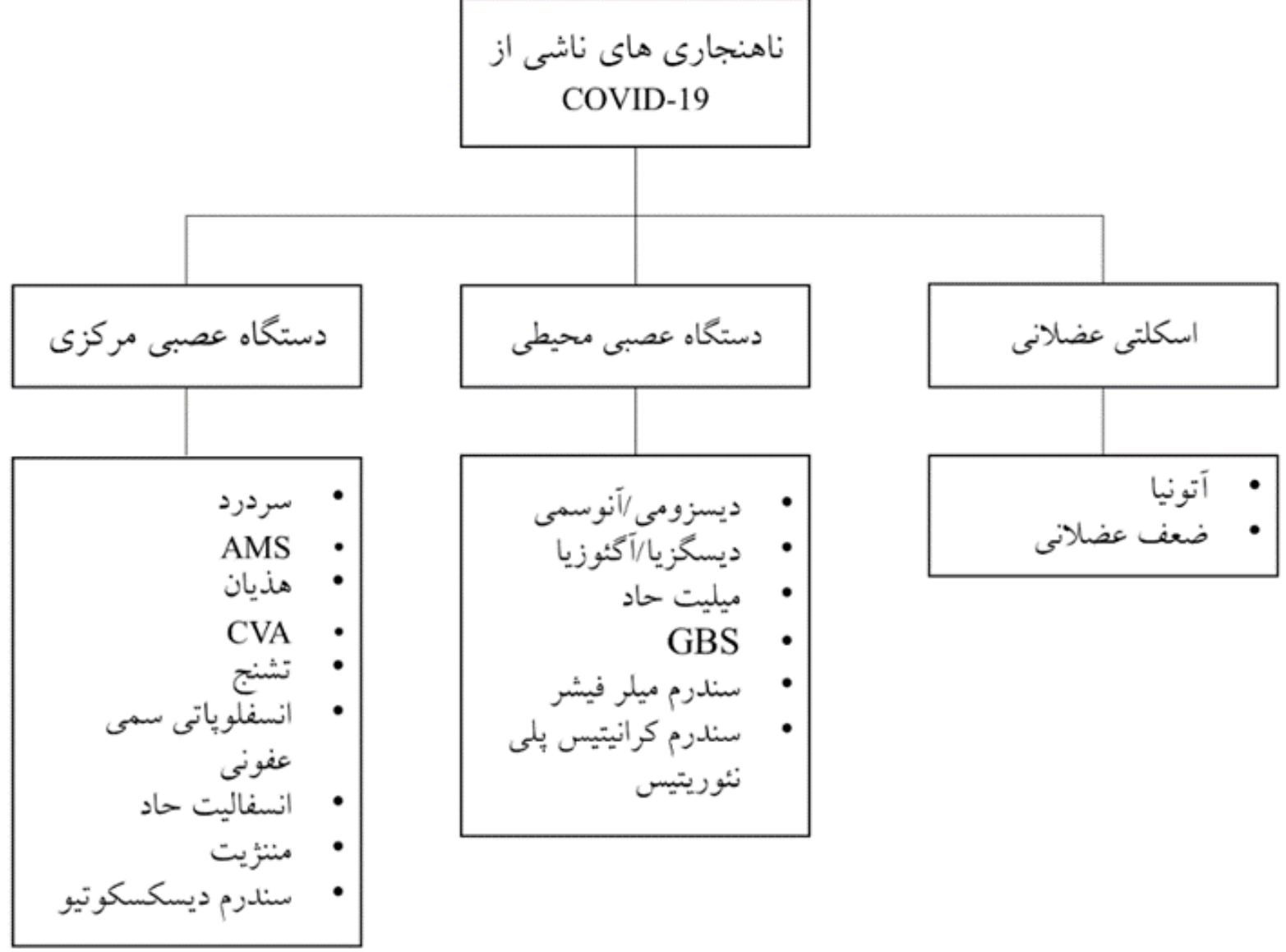

شكل F. خلاصهاى از ناهنجارىهاى عصبى مههم ناشى از ابتلا به COVID-19 [ Sheraton, Deo et al. 2020 ].

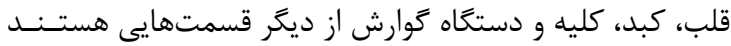

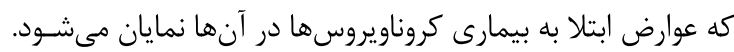

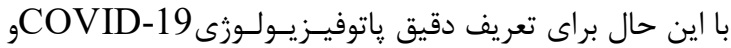

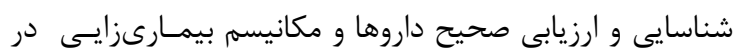

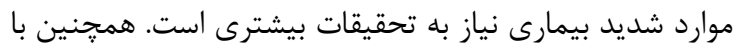

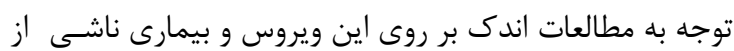

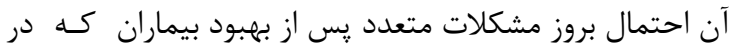

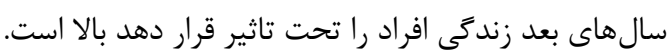

بحث و نتيجه كيرى

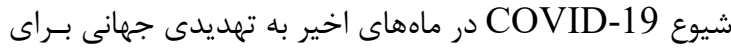
سلامت انسان تبديل شده است. تاثيرات بهداشتى، اقتصادى و و

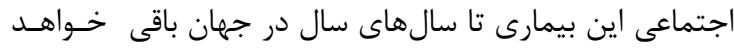

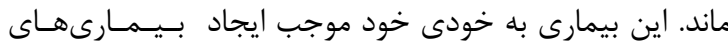

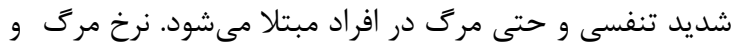

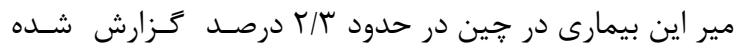

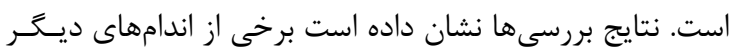

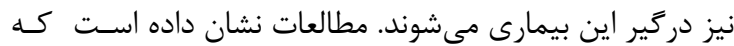




\section{References:}

1-Wang C, Horby PW, Hayden FG, Gao GF. A novel coronavirus outbreak of global health concern. The Lancet. 2020 Feb 15;395 (10223):470-3.

2-Singhal T. A Review of Coronavirus Disease -2019 (COVID-19). Indian journal of pediatrics. 2020;87(4):281-6.

3-Richman DD, Whitley RJ, Hayden FG. Clinical virology: John Wiley \& Sons; 2016.

4-Chan-Yeung $\mathrm{M}, \mathrm{Xu}$ RH. SARS: epidemiology. Respirology. 2003 Nov;8:S9-14. 5-Kampf G, Todt D, Pfaender S, Steinmann E. Persistence of coronaviruses on inanimate surfaces and their inactivation with biocidal agents. Journal of Hospital Infection. 2020 Mar $1 ; 104(3): 246-51$.

6-Rothan HA, Byrareddy SN. The epidemiology and pathogenesis of coronavirus disease (COVID-19) outbreak. Journal of autoimmunity. 2020 Feb 26:102433.

7-Nikpouraghdam M, Farahani AJ, Alishiri G, Heydari S, Ebrahimnia M, Samadinia H, Sepandi M, Jafari NJ, Izadi M, Qazvini A, Dorostkar R. Epidemiological characteristics of coronavirus disease 2019 (COVID-19) patients in IRAN: A single center study. Journal of Clinical Virology. 2020 Apr 21.

8-Pooladi M, Entezari M, Hashemi M, Bahonar A, Hushmandi K, Raei M. Investigating the Efficient Management of Different Countries in the COVID-19 Pandemic. Journal of Marine Medicine. 2020 Apr 10;2(1):18-25.

9-Hushmandi K, Bokaie S, Hashemi M, Moghadam ER, Raei M, Hashemi F, Bagheri M, Habtemariam S, Nabavi SM. A review of medications used to control and improve the signs and symptoms of COVID-19 patients. European journal of pharmacology. 2020 Sep 19:173568.

10-Agrawal U, Raju R, Udwadia ZF. Favipiravir: A new and emerging antiviral option in COVID-19. Medical Journal Armed Forces India. 2020 Sep 2.

11-Li J, Fan JG. Characteristics and mechanism of liver injury in 2019 coronavirus disease. Journal of Clinical and Translational Hepatology. 2020 Mar 28;8(1):13.

12-Yang X, Yu Y, Xu J, Shu H, Liu H, Wu Y, Zhang L, Yu Z, Fang M, Yu T, Wang Y. Clinical course and outcomes of critically ill patients with SARS-CoV-2 pneumonia in Wuhan, China: a single-centered, retrospective, observational study. The Lancet Respiratory Medicine. 2020 Feb 24.

13-Driggin E, Madhavan MV, Bikdeli B, Chuich T, Laracy J, Biondi-Zoccai G, Brown TS, Der Nigoghossian C, Zidar DA, Haythe J, Brodie D. Cardiovascular considerations for patients, health care workers, and health systems during the COVID-19 pandemic. Journal of the American College of Cardiology. 2020 May 12;75(18):2352-71.

14-Boukhris M, Hillani A, Moroni F, Annabi MS, Addad F, Ribeiro MH, Mansour S, Zhao X, Ybarra LF, Abbate A, Vilca LM. Cardiovascular implications of the COVID-19 pandemic: a global perspective. Canadian Journal of Cardiology. 2020 May 16.

15-Huang C, Wang Y, Li X, Ren L, Zhao J, Hu Y, Zhang L, Fan G, Xu J, Gu X, Cheng Z. Clinical features of patients infected with 2019 novel coronavirus in Wuhan, China. The lancet. 2020 Feb 15;395(10223):497-506.

16-Lippi G, Lavie CJ, Sanchis-Gomar F. Cardiac troponin I in patients with coronavirus disease 2019 (COVID-19): Evidence from a meta-analysis. Progress in cardiovascular diseases. 2020 Mar 10.

17-Shi S, Qin M, Shen B, Cai Y, Liu T, Yang F, Gong W, Liu X, Liang J, Zhao Q, Huang H. Association of cardiac injury with mortality in hospitalized patients with COVID-19 in Wuhan, China. JAMA cardiology. 2020 Mar 25.

18-Wang D, Hu B, Hu C, Zhu F, Liu X, Zhang J, Wang B, Xiang H, Cheng Z, Xiong Y, Zhao Y. Clinical characteristics of 138 hospitalized patients with 2019 novel coronavirus-infected pneumonia in Wuhan, China. Jama. 2020 Mar 17;323(11):1061-9.

19-Guo T, Fan Y, Chen M, Wu X, Zhang L, He T, Wang H, Wan J, Wang X, Lu Z. Cardiovascular implications of fatal outcomes of patients with coronavirus disease 2019 (COVID19). JAMA cardiology. 2020 Mar 27

20-Inciardi RM, Lupi L, Zaccone G, Italia L, Raffo M, Tomasoni D, Cani DS, Cerini M, Farina D, Gavazzi E, Maroldi R. Cardiac involvement in a patient with coronavirus disease 2019 (COVID-19). JAMA cardiology. 2020 Mar 27.

21-Esfandiarei M, McManus BM. Molecular biology and pathogenesis of viral myocarditis. Annu. Rev. Pathol. Mech. Dis.. 2008 Feb 28;3:127-55.

22-Xu Z, Shi L, Wang Y, Zhang J, Huang L, Zhang C, Liu S, Zhao P, Liu H, Zhu L, Tai Y. Pathological findings of COVID-19 associated with acute respiratory distress syndrome. The Lancet respiratory medicine. 2020 Apr 1;8 (4):420-2.

23-Rahman JE, Helou EF, Gelzer-Bell R, Thompson RE, Kuo C, Rodriguez ER, Hare JM, Baughman KL, Kasper EK. Noninvasive diagnosis of biopsy-proven cardiac amyloidosis. Journal of the American College of Cardiology. 2004 Feb 4;43(3):410-5. 
24-Liu PP, Mason JW. Advances in the understanding of myocarditis. Circulation. 2001 Aug 28;104(9):1076-82.

25-Andressa Chicatto J, Jefferson Gonçalves M, Altmajer-Vaz D, Ballod Tavares LB. Treatment of the textile wastewater through fungi: a sustainable alternative. Sustainability in Debate/Sustentabilidade em Debate. 2018 Apr 1;9 (1).

26-Chen N, Zhou M, Dong X, Qu J, Gong F, Han Y, Qiu Y, Wang J, Liu Y, Wei Y, Yu T. Epidemiological and clinical characteristics of 99 cases of 2019 novel coronavirus pneumonia in Wuhan, China: a descriptive study. The Lancet. 2020 Feb 15;395(10223):507-13.

27-Liu Y, Yang Y, Zhang C, Huang F, Wang F, Yuan J, Wang Z, Li J, Li J, Feng C, Zhang Z. Clinical and biochemical indexes from 2019 -nCoV infected patients linked to viral loads and lung injury. Science China Life Sciences. 2020 Mar;63(3):364-74.

28-Guan WJ, Ni ZY, Hu Y, Liang WH, Ou CQ, He JX, Liu L, Shan H, Lei CL, Hui DS, $\mathrm{Du}$ B. Clinical characteristics of coronavirus disease 2019 in China. New England journal of medicine. 2020 Apr 30;382(18):1708-20.

29-Liu C, Jiang ZC, Shao CX, Zhang HG, Yue HM, Chen ZH, Ma BY, Liu WY, Huang HH, Yang J, Wang Y. Preliminary study of the relationship between novel coronavirus pneumonia and liver function damage: a multicenter study. Zhonghua gan zang bing za zhi= Zhonghua ganzangbing zazhi $=$ Chinese journal of hepatology. 2020 Feb 20;28(2):148-52.
30-Lu H, Ai J, Shen Y, Li Y, Li T, Zhou X, Zhang H, Zhang Q, Ling Y, Wang S, Qu H. A descriptive study of the impact of diseases control and prevention on the epidemics dynamics and clinical features of SARS-CoV-2 outbreak in Shanghai, lessons learned for metropolis epidemics prevention. Medrxiv. 2020 Jan 1.

31-Cai Q, Huang D, Ou P, Yu H, Zhu Z, Xia Z, Su Y, Ma Z, Zhang Y, Li Z, He Q. COVID19 in a designated infectious diseases hospital outside Hubei Province, China. Allergy. 2020 Apr 2.

32-Li G, Fan Y, Lai Y, Han T, Li Z, Zhou P, Pan P, Wang W, Hu D, Liu X, Zhang Q. Coronavirus infections and immune responses. Journal of medical virology. 2020 Apr;92 (4):424-32.

33-Uhlén M, Fagerberg L, Hallström BM, Lindskog C, Oksvold P, Mardinoglu A, Sivertsson Å, Kampf C, Sjöstedt E, Asplund A, Olsson I. Tissue-based map of the human proteome. Science. 2015 Jan 23;347(6220).

34-Mao L, Wang M, Chen S, He Q, Chang J, Hong C, Zhou Y, Wang D, Miao X, Hu Y, Li Y. Neurological manifestations of hospitalized patients with COVID-19 in Wuhan, China: a retrospective case series study.

35-Bagheri SH, Asghari AM, Farhadi M, Shamshiri AR, Kabir A, Kamrava SK, Jalessi M, Mohebbi A, Alizadeh R, Honarmand AA, Ghalehbaghi B. Coincidence of COVID-19 epidemic and olfactory dysfunction outbreak. Medrxiv. 2020 Jan 1.

36-Mack S, Neha D, Rahul K, Salim S. A Review of Neurological Complications of COVID-19. Cureus. 2020;12(5). 